\title{
Dynamic Characteristics of Encased Differential Gear Train with Journal Bearing
}

\author{
Jie Yang $\left(\mathbb{D},{ }^{1}\right.$ Yanjiong Yue, ${ }^{2}$ Rupeng Zhu $\left(\mathbb{D},{ }^{1}\right.$ Weifang Chen $\left(\mathbb{D},{ }^{1}\right.$ and Miaomiao Li ${ }^{1}$ \\ ${ }^{1}$ National Key Laboratory of Science and Technology on Helicopter Transmission, \\ Nanjing University of Aeronautics and Astronautics, Nanjing 210016, China \\ ${ }^{2}$ The 703 Research Institute of CSIC, Harbin 150078, China \\ Correspondence should be addressed to Rupeng Zhu; rpzhu@nuaa.edu.cn
}

Received 31 October 2019; Accepted 23 March 2020; Published 20 April 2020

Academic Editor: Damijan Markovic

Copyright (C) 2020 Jie Yang et al. This is an open access article distributed under the Creative Commons Attribution License, which permits unrestricted use, distribution, and reproduction in any medium, provided the original work is properly cited.

\begin{abstract}
Taking the marine encased differential gear train as an example, the relationship between the journal bearing parameters and the meshing force of the transmission system is analyzed. In this paper, the dynamic model of the encased differential gear train with journal bearing is established considering the factors of time-varying meshing stiffness and comprehensive transmission error. In this dynamic model, four stiffnesses and four damping coefficients are applied to characterize the asymmetry and interaction of the oil film stiffness and damping of planet bearing. The system responses are calculated by the Fourier series numerical algorithm. The results show that the introduction of journal bearing in encased differential gear train can contribute to gearbox vibration reduction. Moreover, the planet bearing parameters (e.g., clearance-to-radius ratio and eccentricity ratio) of the differential stage affect the meshing forces of both the differential and encased stages. In addition, the influence of the planet bearing parameters of the encased stage on the meshing force of the encased stage is more obvious than that of the differential stage. This work may develop a theoretical analysis framework for the design and manufacture of marine transmission systems in the future.
\end{abstract}

\section{Introduction}

The compound planetary gear train, which performs well in compactness, high power density, and large torque-toweight ratio, is widely used in ship, helicopter, wind turbine, etc. As for heavy machinery transmission systems, journal bearings typically support the carrier and planet in compound planetary gear train, and their stiffness and damping are unequal in all directions [1]. Vibration noise is an important factor affecting the stability and reliability of the gearbox. Studying the dynamic characteristics of a compound planetary gear train may help to reduce the vibration noise.

Some researchers [2-5] focused on the construction of the gear-rotor dynamics model. Using the finite element method, Baguet and Jacquenot [2] established a gearrotor-bearing coupling model, in which the time-varying properties and nonlinearities of gears and bearings were introduced. Gao and Zhang [3] investigated the gearbearing dynamic interactions using a dynamic model of a rotor-bearing system with confluence transmission. Theodossiades and Natsiavas [4] studied the dynamic response of the gear-rotor coupled system under the action of oil film force and meshing force and not only investigated the oil film stability but also analyzed the amplitude-frequency response. Based on nonlinear theory, Wan and Chang [5] carried out a systematic analysis of the dynamic behaviors of a gear-rotor-bearing with strongly nonlinear.

Some scholars have thrown more lights to study the influence of backlash, time-varying meshing stiffness, and manufacturing error on the dynamic characteristics of planetary gear train. Based on elastodynamics, Guo and Parker [6] established a pure torsional dynamic model of the planetary gear train and analyzed the natural frequency and parametric sensitivity. Similarly, Zhang et al. [7] analyzed 
the characteristics of natural frequencies and mode shapes of an encased differential gear train. Wu et al. [8] studied the influence of backlash on the nonlinear characteristics of compound planetary gear set by analyzing the change of backlash with gear wear. Zhu et al. [9] explored the influence of multibacklash on bilateral shock of encased differential planetary gear train. Lin and Parker [10] used a multiscale method to investigate the influence of meshing stiffness waves on the stability of the planetary gear train, and they derived the analytical formula of the relationship between meshing stiffness variation and system dynamic stability. AlShyyab et al. [11] constructed a torsional dynamics model of a discrete two-stage planetary transmission system, and they studied the frequency response of the system under stiffness excitation. Considering time-varying meshing stiffness, Xiang et al. [12] developed a torsional nonlinear dynamic model of multistage planetary gear trains and studied the effects of bifurcation parameters such as excitation frequency, backlash, and damping.

In addition, Iglesias et al. [13] investigated the effects of eccentricity and planet pin positioning errors on the quasistatic behavior of planetary gear train for different configurations of support parameters. In terms of multiple errors (e.g., eccentricity error, base pitch error, and assembly error), Mo et al. [14] proposed an improved mathematical model of the loading sharing coefficient for compound planetary gear train, which was verified by experiments. Using a lumped parameter method, Zhai et al. [15] developed the bending-torsional-pendular coupled vibration model of the wind turbine gearbox transmission system and studied the frequency response of carrier assembly errors (e.g., carrier horizontal assembly error, carrier axis assembly error, and carrier spatial assembly error) to the dynamic meshing force and dynamic transmission error.

In most of the abovementioned studies, the planet bearing assumes a fixed stiffness spring and the bearing force is assumed to be linear with displacement. However, the asymmetry and interaction of oil film stiffness and damping of planet bearing is neglected. To fill this gap, we use four stiffnesses and four damping coefficients to explore the dynamic characteristics of encased differential gear train with journal bearing.

In this study, the marine encased differential gear train with journal bearing is taken as the research object. First, the lumped parameter method is utilized to establish a dynamic model of the encased differential gear train considering time-varying meshing stiffness and comprehensive transmission errors. Second, the asymmetry and interaction of the oil film stiffness and damping of journal bearing is employed to the dynamic model, and the gears and carrier are treated according to the concentrated mass. Third, the time-varying meshing stiffness of herringbone gears is calculated based on the time-varying total contact line length [16]. Fourth, the dynamic equations of coupling journal bearings are constructed by Newton's second law. The dynamic response of encased differential gear train with journal bearing are solved by the numerical algorithm of Fourier series. Finally, the effects of parameters of planet bearing on the meshing forces are explored in detail.

\section{Dynamic Model of Compound Planetary Gear Train}

The encased differential gear train consisting of a singledegree-of-freedom encased planetary gear train (encased stage) and a two-degree-of-freedom differential planetary gear train (differential stage) is shown in Figure 1. In the differential stage, No. 1 , No. 2 , No. 3 , No. 4 , No. 5 , No. 6 , and No. 7 , respectively, represent the floating ring gear $Z_{f 1}$, the intermediate floating member $Z_{g 1}$, the composting ring gear $Z_{r 1}$, the planet $Z_{p i}(i=1,2, \ldots, N$, where $N$ is the number of planets), the sun gear $Z_{s 1}$, the carrier $H$, and planet bearing. In the encased stage, No. 8, No. 9, No. 10, No. 11, No. 12, and No. 13, respectively, represent the floating $\operatorname{ring}$ gear $Z_{f 2}$, the intermediate floating member $Z_{g 2}$, the composting ring gear $Z_{r 2}$, the planet $Z_{m j}(j=1,2, \ldots, M$, where $M$ is the number of planets), and the sun gear $Z_{s 2}$, and planet bearing. No. 14 and No. 15 represent journal bearings at input and output shafts, respectively.

Herringbone gears are employed in the sun gears $Z_{s 1} / Z_{s 2}$ (i.e., No. $5 /$ No. 12 ) and planet $Z_{p i} / Z_{m}$ (i.e., No. $4 /$ No. 11 ). The composting ring gear $Z_{r 1} / Z_{r 2}$ (i.e., No. 3/No. 10) is composed of internal and external helical gears on the same gear tooth germ. The intermediate floating member $Z_{g 1} / Z_{g 2}$ (i.e., No. $2 /$ No. 9) is composed of internal helical and external spur gears on the same gear tooth germ. The internal helical gear of $Z_{r 1} / Z_{r 2}$ meshes with the unilateral helical gear of planet $\mathrm{Z}_{p i} / \mathrm{Z}_{m j}$, and the external helical gear of $Z_{r 1} / Z_{r 2}$ meshes with the internal helical gear of $Z_{g 1} / Z_{g 2}$. The external spur gear of $Z_{g 1} / Z_{g 2}$ meshes with the internal spur gear of $Z_{f 1} / Z_{f 2}$ (i.e., No. 1 /No. 8).

Figure 2 shows the dynamic model of the encased differential gear train. The rotational coordinate system based on the rotation angular velocity of carrier $H$ is applied to the differential stage. The fixed coordinate system is used for the encased stage. The degree-of-freedom of the encased differential gear train is $19+3(N+M)$. Displacement parameter $X$ is defined by

$$
\begin{aligned}
X= & \left\{x_{s 1}, H_{s 1}, V_{s 1}, x_{p i}, H_{p i}, V_{p i}, x_{r 1}, H_{r 1}, V_{r 1}, x_{g 1},\right. \\
& x_{f 1}, x_{s 2}, H_{s 2}, V_{s 2}, x_{m j}, H_{m j}, V_{m j}, x_{r 2}, H_{r 2}, V_{r 2}, \\
& \left.x_{g 2}, x_{f 2}, x_{H}, H_{H}, V_{H}\right\}
\end{aligned}
$$

where $x_{\mathrm{s} 1}, x_{\mathrm{p} i}, x_{\mathrm{r} 1}, x_{\mathrm{s} 2}, x_{\mathrm{m} j}$, and $x_{\mathrm{r} 2}$ are torsional line displacement parameters along base circle radius of $Z_{s 1}, Z_{p i}, Z_{r 1}$, $Z_{s 2}, Z_{m j}$, and $Z_{r 2}$, respectively. $x_{\mathrm{g} 1}, x_{\mathrm{f} 1}, x_{\mathrm{g} 2}$, and $x_{\mathrm{f} 2}$ are torsional line displacement parameters along the pitch circle radius of $Z_{f 1}, Z_{g 1}, Z_{f 2}$, and $Z_{g 2}$, respectively. $x_{H}, H_{H}$, and $V_{H}$ are torsional, lateral, and longitudinal displacements of carrier $H$, respectively. $H_{\mathrm{s} 1}, H_{\mathrm{p} i}$, and $H_{\mathrm{r} 1}$ are lateral center displacements of $Z_{s 1}, Z_{p i}$, and $Z_{r 1}$, respectively, in their rotational coordinates. $V_{s i}, V_{p i}$, and $V_{r 1}$ are longitudinal center displacements of $Z_{s 1}, Z_{p i}$, and $Z_{r 1}$, respectively, in their rotational coordinates. $H_{\mathrm{s} 2}, H_{\mathrm{m} j}$, and $H_{r 2}$ are lateral center displacements of $Z_{s 2}, Z_{m i}$, and $Z_{r 2}$, respectively, in fixed coordinate. $V_{s 2}, V_{m j}$, and $V_{r 2}$ are longitudinal center displacements of $Z_{s 2}, Z_{m j}$, and $Z_{r 2}$, respectively, in fixed coordinate. 


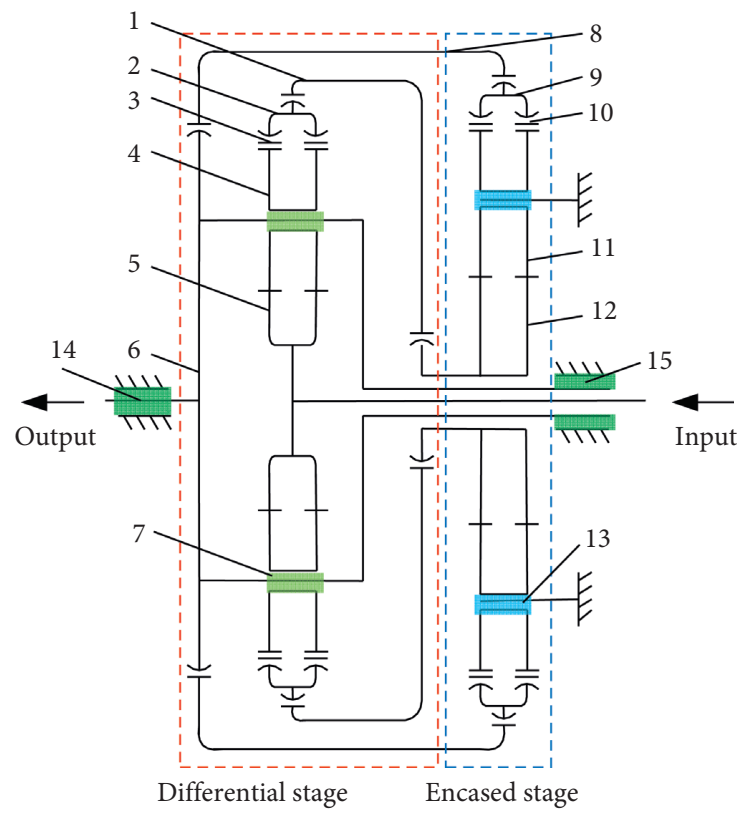

FIgURE 1: Diagram of the transmission system.

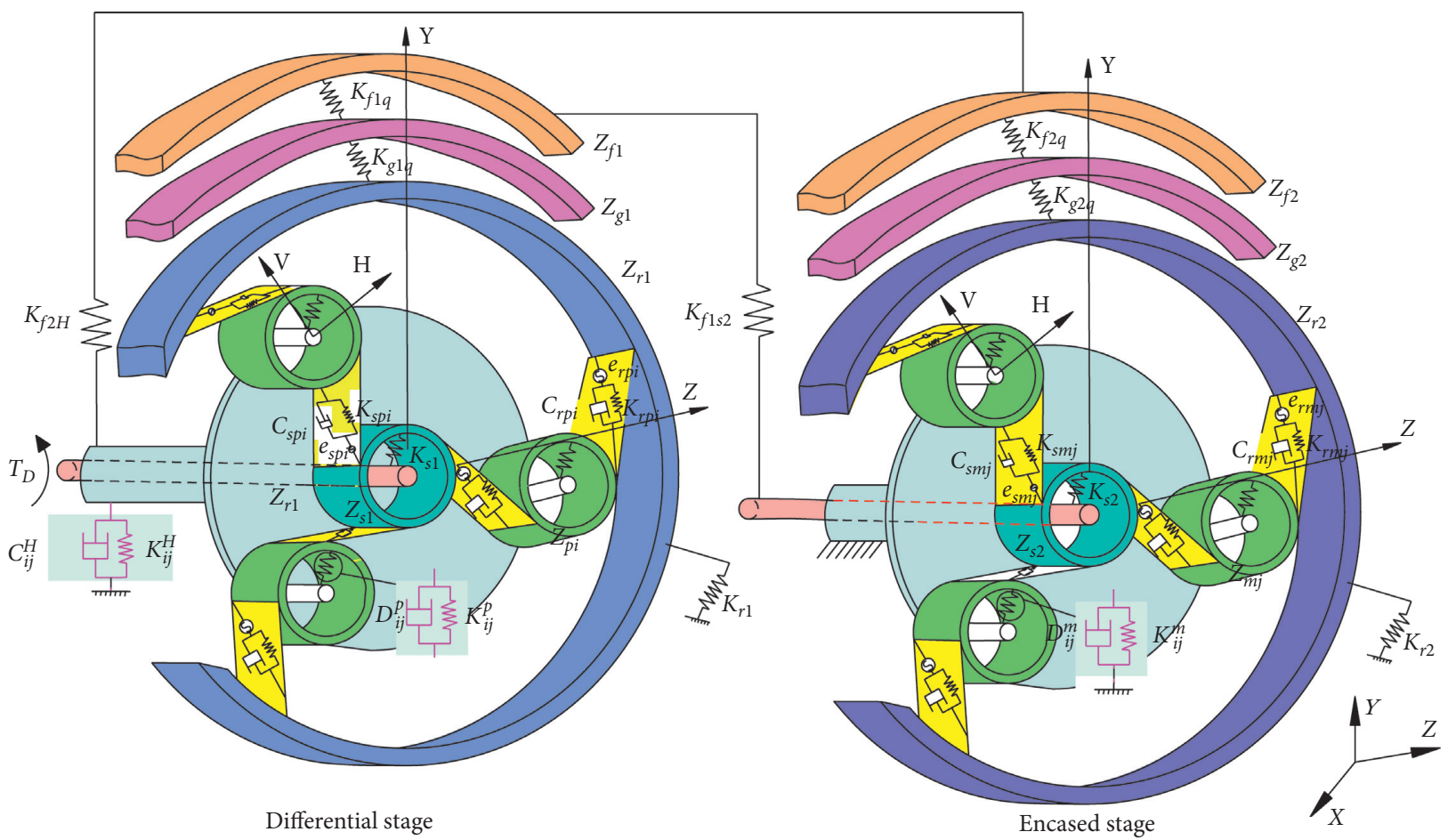

Figure 2: Dynamic model of the encased differential gear train.

2.1. Model for Calculation of Journal Bearing Stiffness and Damping. The dynamic model of the journal bearing is shown in Figure 3. Assuming that displacement and velocity remain small disturbances in the vicinity of the static position $O_{0}\left(x_{0}, y_{0}\right)[1]$, the first-order expansion of dynamic bearing forces (i.e., $F_{x}$ and $F_{y}$ ) is defined bywhere $\left.\left(\partial F_{i} / \partial j\right)\right|_{0}(i=x, y ; j=x, y, \dot{x}, \dot{y})$ is the partial derivative at static position $O_{0}\left(x_{0}, y_{0}\right)$.

$$
\left\{\begin{array}{l}
F_{x} \approx F_{x 0}+\left.\frac{\partial F_{x}}{\partial x}\right|_{0}\left(x-x_{0}\right)+\left.\frac{\partial F_{x}}{\partial y}\right|_{0}\left(y-y_{0}\right)+\left.\frac{\partial F_{x}}{\partial x}\right|_{0} \dot{x}+\left.\frac{\partial F_{x}}{\partial x}\right|_{0} \dot{y}, \\
F_{y} \approx F_{y 0}+\left.\frac{\partial F_{y}}{\partial x}\right|_{0}\left(x-x_{0}\right)+\left.\frac{\partial F_{y}}{\partial y}\right|_{0}\left(y-y_{0}\right)+\left.\frac{\partial F_{y}}{\partial x}\right|_{0} \dot{x}+\left.\frac{\partial F_{y}}{\partial y}\right|_{0} \dot{y},
\end{array}\right.
$$

Here, 


$$
\left\{\begin{array}{l}
k_{i j}=\left.\frac{\partial F_{i}}{\partial j}\right|_{0}(i=x, y ; j=x, y), \\
d_{i j}=\left.\frac{\partial F_{i}}{\partial j}\right|_{0}(i=x, y ; j=\dot{x}, \dot{y}), \\
\Delta F_{x}=F_{x}-F_{x 0}=k_{x x} \xi+k_{x y} \eta+d_{x x} \dot{\xi}+d_{x y} \dot{\eta}, \\
\Delta F_{y}=F_{y}-F_{y 0}=k_{y x} \xi+k_{y y} \eta+d_{y x} \dot{\xi}+d_{y y} \dot{\eta},
\end{array}\right.
$$

where $F_{x 0}$ and $F_{y 0}$ are static bearing forces in $x$ and $y$ directions, respectively. $\Delta F_{x}$ and $\Delta F_{y}$ are the increments of the oil film force. $\xi$ and $\eta$ are the increments of oil-film thickness in $x$ and $y$ directions, respectively. $k_{i j}$ and $d_{i j}(i, j=x, y)$ are the stiffness and damping coefficients of journal bearing, which are obtained by

$$
\left\{\begin{array}{l}
k_{i j}=K_{i j} \frac{\mu \omega B}{\psi^{3}}, \\
d_{i j}=D_{i j} \frac{\mu B}{\psi^{3}}(i, j=x, y), \\
K_{x x}=\left(\frac{B}{d}\right)^{2} \frac{4 \varepsilon\left[2 \pi^{2}+\left(16-\pi^{2}\right) \varepsilon^{2}\right]}{\left(1-\varepsilon^{2}\right)^{2}\left[16 \varepsilon^{2}+\pi^{2}\left(1-\varepsilon^{2}\right)\right]} \\
D_{x y}=\left(\frac{B}{d}\right)^{2} \frac{2 \pi\left[\pi^{2}+2 \pi^{2} \varepsilon^{2}-16 \varepsilon^{2}\right]}{\left(1-\varepsilon^{2}\right)^{2}\left[16 \varepsilon^{2}+\pi^{2}\left(1-\varepsilon^{2}\right)\right]} \\
K_{y y}=\left(\frac{B}{d}\right)^{2} \frac{\pi\left[-\pi^{2}+2 \pi^{2} \varepsilon^{2}+\left(16-\pi^{2}\right) \varepsilon^{4}\right]}{\left(1-\varepsilon^{2}\right)^{(5 / 2)}\left[16 \varepsilon^{2}+\pi^{2}\left(1-\varepsilon^{2}\right)\right]} \\
D_{x y}=\left(\frac{B}{d}\right)^{2} \frac{8 \varepsilon\left[\pi^{2}+12 \pi^{2} \varepsilon^{2}-16 \varepsilon^{2}\right]}{\left(1-\varepsilon^{2}\right)^{2}\left[16 \varepsilon^{2}+\pi^{2}\left(1-\varepsilon^{2}\right)\right]} \\
K_{y x}=\left(\frac{B}{d}\right)^{2} \frac{\pi\left[\pi^{2}+\left(\pi^{2}+32\right) \varepsilon^{2}+2\left(16-\varepsilon^{2}\right)^{2}\left[16 \varepsilon^{2}+\pi^{2}\left(1-\varepsilon^{2}\right)\right]\right.}{\left(1-\varepsilon^{2}\right)^{(5 / 2)}\left[16 \varepsilon^{2}+\pi^{2}\left(1-\varepsilon^{2}\right)\right]} \\
D_{x y},
\end{array}\right.
$$

where $B$ and $d$ are the width and diameter of the journal bearing, $\mu$ is the oil viscosity, $\varepsilon$ is the eccentricity ratio, $\psi$ is the clearance-to-radius ratio, and $K_{i j}$ and $D_{i j}(i, j=x, y)$ are the corresponding dimensionless stiffness and damping coefficient of journal bearing.

\subsection{Model for Calculation of Time-Varying Meshing Stiffness.} The planets are evenly distributed among the sun gear in the planetary gear train. There are varying mesh phasing factors in meshing pairs (i.e., sun-planet and ring-planet) because of the

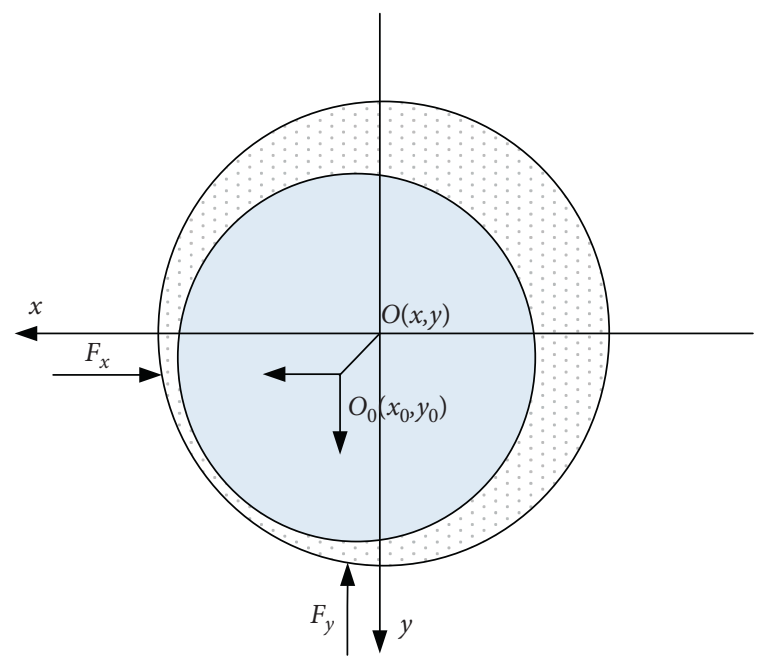

FIGURE 3: Dynamic model of journal bearing.

influence of the number of teeth. The mesh phasing factor affects the phase of the time-varying meshing stiffness [17]. Therefore, the mesh phasing factor is incorporated into the encased differential gear train. Following Parker and Lin [18], the mesh phasing factor is defined by

$$
\left\{\begin{array}{l}
\gamma_{s m}=\left(\frac{Z_{s} \psi_{m}}{2 \pi}\right), \\
\gamma_{r m}=-\left(\frac{Z_{r} \psi_{m}}{2 \pi}\right),
\end{array}\right.
$$

where $\gamma_{s m}$ and $\gamma_{r m}$ are the mesh phasing factor of sun-planet and ring-planet, respectively, and $Z_{s}$ and $Z_{r}$ are the teeth number of the sun and ring, respectively.

Maatar and Velex [16] proposed the time-varying meshing stiffness of helical gear pairs based on the timevarying total contact line length. Following Maatar and Velex [16], the time-varying meshing stiffness model of the helical gear is applied to the herringbone gear by a parallel method in this study. The time-varying meshing stiffness model of the herringbone gear is constructed as follows:

$$
k(t)=2 k_{0} L(\tau)
$$

where $k_{0}$ is the average value of the time-varying meshing stiffness, $\tau$ is dimensionless time, $\tau=t / T_{m}, t$ and $T_{m}$ are meshing time and period, and $L(\tau)$ is the instantaneous total contact length of gear pair, which is obtained by

$$
L(\tau)=\left(1+\sum_{k=1}^{S}\left[A_{k} \cos (2 \pi k \tau-\gamma)+B_{k} \sin (2 \pi k \tau-\gamma)\right]\right) \frac{b \varepsilon_{\alpha}}{\cos \beta_{b}},
$$

where $\gamma$ is the mesh phasing factor, $\varepsilon_{\alpha}$ is the end-face contact ratio of the herringbone gear, $\beta_{b}$ is the helical angle of the base circle of the herringbone gear, $B$ is the unilateral tooth width of the herringbone gear, $A_{k}$ and $B_{k}$ are the $k$ th-order harmonic amplitude of the time-varying meshing stiffness, $S$ represents the order of the Fourier series, and the series is truncated at $S=5$ in this article. 
The parameters $A_{k}$ and $B_{k}$ are calculated by

$$
\left\{\begin{array}{l}
A_{k}=\frac{1}{2 \varepsilon_{\alpha} \varepsilon_{\beta} \pi^{2} k^{2}}\left[\cos \left(2 \pi k \varepsilon_{\beta}\right)+\cos \left(2 \pi k \varepsilon_{\alpha}\right)-\cos \left[2 \pi k\left(\varepsilon_{\alpha}+\varepsilon_{\beta}\right)\right]-1\right] \\
B_{k}=\frac{1}{2 \varepsilon_{\alpha} \varepsilon_{\beta} \pi^{2} k^{2}}\left[\sin \left(2 \pi k \varepsilon_{\beta}\right)+\sin \left(2 \pi k \varepsilon_{\alpha}\right)-\sin \left(2 \pi k\left(\varepsilon_{\alpha}+\varepsilon_{\beta}\right)\right)\right]
\end{array}\right.
$$

where $\varepsilon_{\beta}$ is axial contact ratio of the herringbone gear.

2.3. The Equivalent Displacement and Meshing Forces. The center displacement of each gear is projected into the meshing line direction. We ignored the change of the meshing angle caused by the movement of each gear center. Figure 4 shows the positional relationship sun gear, planet, and composting ring gear in the differential stage.

The equivalent displacement of the $i$ th planet-composting ring and sun-planet along meshing line direction can be calculated by

$$
\left\{\begin{array}{l}
S_{r p i}(t)=x_{p i}-x_{r 1}+H_{p i} \sin \alpha_{r p}-V_{p i} \cos \alpha_{r p} \\
\quad-H_{r 1} \sin \left(\alpha_{r p}+\psi_{i}\right)+V_{r 1} \cos \left(\alpha_{r p}+\psi_{i}\right)-e_{r p i}(t) \\
S_{s p i}(t)=x_{s 1}-x_{p i}+H_{s 1} \sin \left(\alpha_{s p}-\psi_{i}\right)+V_{s 1} \cos \left(\alpha_{s p}-\psi_{i}\right) \\
\quad-H_{p i} \sin \alpha_{s p}-V_{p i} \cos \alpha_{s p}-e_{s p i}(t)
\end{array}\right.
$$

where $e_{r p i}$ and $e_{s p i}$ are the equivalent error of the $i$ th planetcomposting ring and sun-planet along meshing line direction.

According to the equivalent displacement calculation method of the differential stage, the equivalent displacement of the $j$ th sun-planet and composting ring-planet along meshing line direction can be calculated by

$$
\left\{\begin{array}{l}
S_{r m j}(t)=x_{m j}-x_{r 2}+H_{m j} \sin \alpha_{r m}-V_{m j} \cos \alpha_{r m}, \\
\quad-H_{r 2} \sin \left(\alpha_{r m}+\psi_{j}\right)+V_{r 2} \cos \left(\alpha_{r m}+\psi_{j}\right)-e_{r m j}(t) \\
S_{s m j}(t)=x_{s 2}-x_{m j}+H_{s 2} \sin \left(\alpha_{s m}-\psi_{j}\right)+V_{s 2} \cos \left(\alpha_{s m}-\psi_{j}\right), \\
\quad-H_{m j} \sin \alpha_{s m}-V_{m j} \cos \alpha_{s m}-e_{s m j}(t) .
\end{array}\right.
$$

The planet is supported by planet bearing in the encased differential gear train, and thus the compression deformation between carrier and planet bearing can be obtained by

$$
\left\{\begin{array}{l}
\delta_{H c p i}=H_{c} \cos \psi_{i}+V_{c} \sin \psi_{i}-H_{p i}, \\
\delta_{V c p i}=-H_{c} \sin \psi_{i}+V_{c} \cos \psi_{i}-V_{p i}-x_{c}
\end{array}\right.
$$

where $\delta_{H c p i}$ is the compression deformation of planet bearing along the lateral direction and $\delta_{V c p i}$ is the compression deformation along the longitudinal direction.

Elastic and damping meshing forces in the differential and encased stages can be calculated by

$$
\left\{\begin{array}{l}
F_{i}(t)=K_{i}(t) S_{i}(t) \\
D_{i}(t)=C_{i} \dot{S}_{i}(t)
\end{array}, \quad i=s p i, r p i, s m j, \text { and } r m j,\right.
$$

where $\dot{S}_{i}(t)$ is the first derivative of equivalent displacement. $C_{i}$ is the meshing damping factor, which can be calculated by [19]

$$
C_{i}=2 \xi_{i} \sqrt{\frac{k_{0, i}}{\left(1 / m_{p i}\right)+\left(1 / m_{g i}\right)}}, \quad i=s p i, r p i, s m j \text {, and } r m j \text {, }
$$

where $\zeta_{i}$ denotes the constant damping ratios of the gear pair, $\zeta_{i}=0.07 ; k_{0, i}$ represents the average value of the meshing stiffness in the gear pair, and $m_{p i}$ and $m_{g i}$ are the masses of the driving and driven gears in the gear pair.

\subsection{Differential Equations of the Compound Planetary Gear} Trains. According to Figure 2 of the dynamic model of the encased differential gear train, differential equations of $19+3(N+M)$ degree-of-freedom are constructed for the encased differential gear train by the lumped parameter method. Differential equations of the differential stage can be deduced using Newton's second law as follows.

(1) The sun gear $Z_{s 1}$ :

$$
\left\{\begin{array}{l}
m_{s 1} \ddot{x}_{s 1}+\sum_{i=1}^{N}\left(F_{s p i}(t)+D_{s p i}(t)\right)=P_{D} \\
M_{s 1} \ddot{H}_{s 1}+\sum_{i=1}^{N}\left(F_{s p i}(t)+D_{s p i}(t)\right) \sin \left(\alpha_{s p}-\psi_{i}\right)+K_{s 1} H_{s 1}=-M_{s 1} g \sin \left(\omega_{H} t\right) \\
M_{s 1} \ddot{V}_{s 1}+\sum_{i=1}^{N}\left(F_{s p i}(t)+D_{s p i}(t)\right) \cos \left(\alpha_{s p}-\psi_{i}\right)+K_{s 1} V_{s 1}=-M_{s 1} g \cos \left(\omega_{H} t\right)
\end{array}\right.
$$




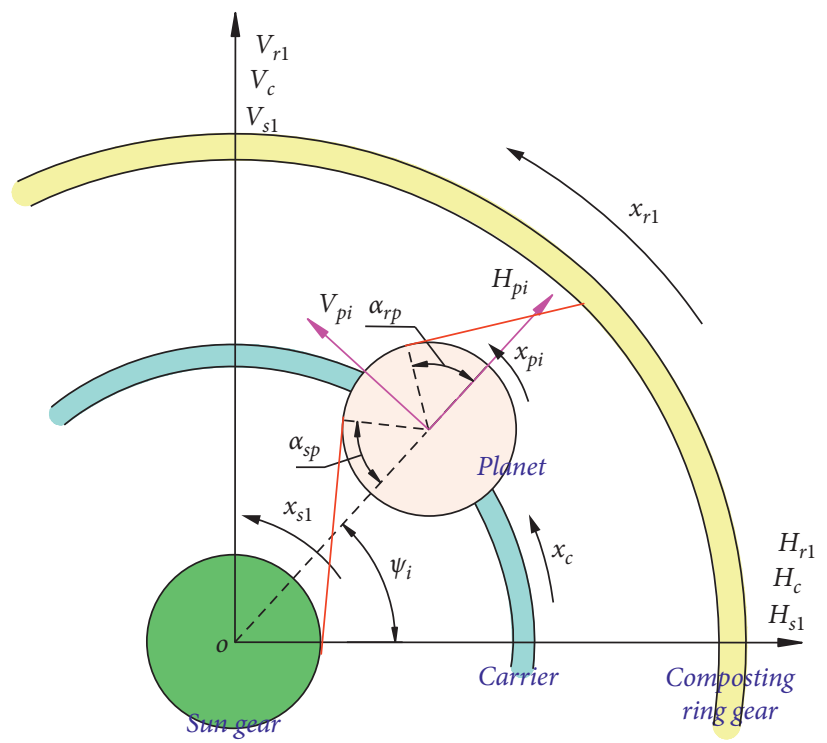

FIgURE 4: Position relationship of each component in the differential stage.

(2) The ith planet gear $Z_{p i}$ :

$$
\left\{\begin{array}{l}
m_{p} \ddot{x}_{p i}-\left(F_{s p i}(t)+D_{s p i}(t)\right)+\left(F_{r p i}(t)+D_{r p i}(t)\right)=0, \\
M_{p} \ddot{H}_{p i}-\left(F_{s p i}(t)+D_{s p i}(t)\right) \sin \alpha_{s p}+\left(F_{r p i}(t)+D_{r p i}(t)\right) \sin \alpha_{r p} \\
\quad+F_{H c p i}(t)=-M_{p i} g \sin \left(\omega_{H} t+\psi_{i}\right)+F_{p i}, \\
M_{p} \ddot{V}_{p i}-\left(F_{s p i}(t)+D_{s p i}(t)\right) \cos \alpha_{s p}+\left(F_{r p i}(t)+D_{r p i}(t)\right) \cos \alpha_{r p} \\
\quad+F_{V c p i}(t)=-M_{p i} g \cos \left(\omega_{H} t+\psi_{i}\right),
\end{array}\right.
$$

where $F_{H c p i}(t)$ is the oil film force of the $i$ th planet bearing in the lateral direction, $F_{V c p i}(t)$ is the oil film force of the $i$ th planet bearing in the longitudinal direction, $F_{H c p i}(t)$ and $F_{V c p i}(t)$ are calculated by equation (3), and $F_{p i}$ is the centrifugal force of the $i$ th planet $\mathrm{Z}_{p i}$.

(3) The composting ring gear $Z_{r 1}$ :

$$
\left\{\begin{array}{l}
m_{r 1} \ddot{x}_{r 1}-\sum_{i=1}^{N}\left(F_{r p i}(t)+D_{r p i}(t)\right)+k_{g 1 q}\left(x_{r 1}-x_{g 1}\right)=0 \\
M_{r 1} \ddot{H}_{r 1}-\sum_{i=1}^{N}\left(F_{r p i}(t)+D_{r p i}(t)\right) \sin \left(\alpha_{r p}+\psi_{i}\right)+K_{r 1} H_{r 1}=-M_{r 1} g \sin \left(\omega_{H} t\right) \\
M_{r 1} \ddot{V}_{r 1}+\sum_{i=1}^{N}\left(F_{r p i}(t)+D_{r p i}(t)\right) \cos \left(\alpha_{r p}+\psi_{i}\right)+K_{r 1} V_{r 1}=-M_{r 1} g \cos \left(\omega_{H} t\right) .
\end{array}\right.
$$


(4) The intermediate floating member $Z_{g 1}$ and floating $\operatorname{ring} Z_{f 1}$ :

$$
\left\{\begin{array}{l}
m_{g 1} \ddot{x}_{g 1}-K_{g 1 q}\left(x_{r 1}-x_{g 1}\right)+K_{f 1 q}\left(x_{g 1}-x_{f 1}\right)=0, \\
m_{f 1} \ddot{x}_{f 1}-K_{f 1 q}\left(x_{g 1}-x_{f 1}\right)+\frac{K_{f 1 s 2}}{r_{f 1 b}}\left(\frac{x_{f 1}}{r_{f 1 b}}-\frac{x_{s 2}}{r_{s 2 b}}\right)=0 .
\end{array}\right.
$$

Differential equations of the encased stage can be deduced using Newton's second law as follows:

(1) The sun gear $Z_{s 2}$ :

$$
\left\{\begin{array}{l}
m_{s 2} \ddot{x}_{s 2}-\frac{K_{f 1 s 2}}{r_{s 2 b}}\left(\frac{x_{f 1}}{r_{f 1 b}}-\frac{x_{s 2}}{r_{s 2 b}}\right)+\sum_{j=1}^{M}\left(F_{s m j}(t)+D_{s m j}(t)\right)=0, \\
M_{s 2} \ddot{H}_{s 2}+\sum_{j=1}^{M}\left(F_{s m j}(t)+D_{s m j}(t)\right) \sin \left(\alpha_{s m}-\psi_{j}\right)+K_{s 2} H_{s 2}=0, \\
M_{s 2} \ddot{V}_{s 2}+\sum_{j=1}^{M}\left(F_{s m j}(t)+D_{s m j}(t)\right) \cos \left(\alpha_{s m}-\psi_{j}\right)+K_{s 2} V_{s 2}=-M_{s 2} g .
\end{array}\right.
$$

(2) The $j$ th planet gear $Z_{m j}$ :

$$
\left\{\begin{array}{l}
m_{m} \ddot{x}_{m j}-\left(F_{s m j}(t)+D_{s m j}(t)\right)+\left(F_{r m j}(t)+D_{r m j}(t)\right)=0, \\
M_{m} \ddot{H}_{m j}-\left(F_{s m j}(t)+D_{s m j}(t)\right) \sin \alpha_{s m}+\left(F_{r m j}(t)+D_{r m j}(t)\right) \sin \alpha_{r m}+F_{H m j}(t)=-M_{m} g \sin \left(\psi_{j}\right), \\
M_{m} \ddot{V}_{m j}-\left(F_{s m j}(t)+D_{s m j}(t)\right) \cos \alpha_{s m}+\left(F_{r m j}(t)+D_{r m j}(t)\right) \cos \alpha_{r m}+F_{V m j}(t)=-M_{m} g \cos \left(\psi_{j}\right),
\end{array}\right.
$$

where $F_{H m j}(t)$ is the oil film force of the $j$ th planet bearing in the lateral direction and $F_{V m j}(t)$ is the oil (3) The composting ring gear $Z_{r 2}$ : film force of the $j$ th planet bearing in the longitudinal direction.

$$
\left\{\begin{array}{l}
m_{r 2} \ddot{x}_{r 2}-\sum_{j=1}^{M}\left(F_{r m j}(t)+D_{r m j}(t)\right)+k_{g 2 q}\left(x_{r 2}-x_{g 2}\right)=0 \\
M_{r 2} \ddot{H}_{r 2}-\sum_{j=1}^{M}\left(F_{r m j}(t)+D_{r m j}(t)\right) \sin \left(\alpha_{r m}+\psi_{j}\right)+K_{r 2} H_{r 2}=0 \\
M_{r 2} \ddot{V}_{r 2}+\sum_{i=1}^{M}\left(F_{r m j}(t)+D_{r m j}(t)\right) \cos \left(\alpha_{r m}+\psi_{j}\right)+K_{r 2} V_{r 2}=-M_{r 2} g
\end{array}\right.
$$

(4) The intermediate floating member $Z_{g 2}$ and floating ring $Z_{f 2}$ :

$$
\left\{\begin{array}{l}
m_{g 2} \ddot{x}_{g 2}-K_{g 2 q}\left(x_{r 2}-x_{g 2}\right)+K_{f 2 q}\left(x_{g 2}-x_{f 2}\right)=0 \\
m_{f 2} \ddot{x}_{f 2}-K_{f 2 q}\left(x_{g 2}-x_{f 2}\right)+\frac{K_{f 2 L}}{r_{f 2 b}}\left(\frac{x_{f 2}}{r_{f 2 b}}-\frac{x_{c}}{r_{c}}\right)=0 .
\end{array}\right.
$$


The differential equation of carrier $H$ can be deduced by Newton's law:

$$
\left\{\begin{array}{l}
m_{c} \ddot{x}_{c}+\sum_{i=1}^{N} F_{V c p i}+\frac{K_{c H}}{r_{c}} \frac{x_{c}}{r_{c}}-\frac{K_{f 2 H}}{r_{c}}\left(\frac{x_{f 2}}{r_{f 2 b}}-\frac{x_{c}}{r_{c}}\right)=-\frac{T_{L}}{r_{c}}, \\
M_{c} \ddot{H}_{c}+\sum_{i=1}^{N}\left(F_{H c p i} \cos \psi_{i}-F_{V c p i} \sin \psi_{i}\right)+F_{c}^{H}=0, \\
M_{c} \ddot{V}_{c}+\sum_{i=1}^{N}\left(F_{H c p i} \sin \psi_{i}+F_{V c p i} \cos \psi_{i}\right)+F_{c}^{V}=-M_{c} g,
\end{array}\right.
$$

where $F_{c}^{H}$ is the oil film force of journal bearing in the lateral direction and $F_{c}^{V}$ is the oil film force of journal bearing in the longitudinal direction.

\section{Numerical Studies and Analysis}

The dynamics simulation is performed with a constant power of $1000 \mathrm{~kW}$. Different rotational speeds are applied to the differential stage sun gear. Table 1 lists the parameters of the encased differential gear train. The system response is solved by the numerical calculation method of the Fourier series [20]. The eccentricity ratio of the journal bearing is taken from 0.01 to 0.91 . The clearance-to-radius ratio ranges from $0.1 \%$ to $2.5 \%$. The oil viscosity is $0.04 \mathrm{~N} \cdot \mathrm{s} / \mathrm{m}^{2}$.

\subsection{Comparative Analysis of Spring Bearing and Journal} Bearing. Before performing planet bearing parameter analysis, we calculate the dynamic deviation of the meshing force to investigate whether the encased differential gear train with journal bearing is more stable than the encased differential gear train with spring (i.e., planet bearings are replaced by fixed stiffness springs). The dynamic model of the encased differential gear train with spring is constructed by equations (14)-(22), and the stiffness of spring is $6 \times 10^{6} \mathrm{~N} / \mathrm{m}$. According to the stiffness and damping coefficient of the journal bearing in Section 2.1, we establish the dynamic model of the encased differential planetary gear train with journal bearing. The dynamic deviation of meshing force (i.e., the degree of dynamic meshing force deviates from the theoretical static meshing force) is defined as follows [21]:

$$
\left\{\begin{array}{l}
S_{e}=\frac{1}{N} \sum_{j=1}^{N} \sqrt{(1 / Q) \sum_{i=1}^{Q}\left(F_{j i}^{e}-F_{s}\right)^{2}} \\
S_{i}=\frac{1}{N} \sum_{j=1}^{N} \sqrt{(1 / Q) \sum_{i=1}^{Q}\left(F_{j i}^{i}-F_{s}\right)^{2}}
\end{array}\right.
$$

where $S_{e}$ and $S_{i}$ represent the dynamic deviation of external and internal meshing forces, respectively, $N$ is the number of planets, $Q$ is the sampling times of the dynamic meshing force, $F_{i j}^{e}$ and $F_{i j}^{i}$ are external and internal instantaneous meshing force, respectively, and $F_{s}$ is the theoretical static meshing force.

Figure 5(a) shows that, in the differential stage, the dynamic deviation curves of the external meshing force of the bearing model and the spring model are basically the same at a low rotational speed. However, the dynamic deviation curve of the external meshing force of the spring model has a peak when the rotational speed is $4800 \mathrm{r} / \mathrm{min}$. It is worth noting that the dynamic deviation curve of the internal meshing force is approximately the same as that of the external meshing force (see Figures 5(a) and 5(b)). Figures 5(c) and 5(d) detail that, in the encased stage, the dynamic deviation curves of the meshing forces of the bearing model and the spring model are substantially the same. These findings indicate that at high rotational speeds, the oil film force of journal bearing can curb the vibration of the encased differential gear train. Therefore, we investigate the influence of the parameters of planet bearings on dynamic meshing forces in the next step.

\subsection{Influence of the Differential Planet Bearing Parameters on} Meshing Forces. After modeling differential equations of the encased differential gear train with journal bearing, the dynamic meshing force of differential equations can be calculated by equation (12). Besides, we use the root-meansquare to describe dynamic meshing forces.

3.2.1. Clearance-to-Radius Ratio. To investigate the effects of the differential planet bearing clearance-to-radius ratios on meshing forces, we set the clearance-to-radius ratio as $0.1 \%$, $0.5 \%$, $1 \%$, $1.5 \%$, $2 \%$, and $2.5 \%$, respectively (see Figure 6). The amplitude-frequency response curves of the meshing forces within the rotation speed range of 500-6000 r/min are calculated.

Figures 6(a) and 6(b) report that the amplitude-frequency response curves of meshing forces (i.e., external and internal) in the differential stage overlap at low rotational speed and diverge at a high rotational speed. This finding indicates that the impact of the clearance-to-radius ratio of the differential planet bearing on the meshing force is small when the rotational speed is low; the impact of clearance-toradius ratio on the meshing force is obvious when the rotational speed is high. Figures 6(c) and 6(d) show that the amplitude-frequency response curves of meshing forces in the encased stage tend to diverge at low rotational speed and tend to overlap at a high rotational speed. Therefore, when the rotational speed in the encased planetary gear train is low, the clearance-to-radius ratio of the differential planet bearing should be reduced to diminish its influence on the meshing force to ensure the stability and reliability of the system.

3.2.2. Eccentricity Ratio. To investigate the influence of the eccentricity ratio of the differential planet bearing on meshing forces, the eccentricity ratios amount on the planet bearing are taken as $0.01,0.19,0.37,0.55,0.73$, and 0.91 , respectively. We calculate the amplitude-frequency response 
TABLE 1: The parameters of the encased differential gear train.

\begin{tabular}{|c|c|c|c|c|c|c|}
\hline & $Z_{s 1} / Z_{s 2}$ & $Z_{p i} / Z_{m j}$ & $Z_{r 1} / Z_{r 2}$ & $Z_{g 1} / Z_{g 2}$ & $Z_{f 1} / Z_{f 2}$ & $H$ \\
\hline Teeth number & $38 / 98$ & $96 / 53$ & $232 / 202$ & $251 / 231$ & $375 / 348$ & - \\
\hline Module & 2.5 & 2.5 & 2.5 & 2.5 & 2 & - \\
\hline Helix angle $\left({ }^{\circ}\right)$ & 25 & 25 & 25 & 25 & 0 & - \\
\hline Pressure angel $\left({ }^{\circ}\right)$ & 20 & 20 & 20 & 20 & 20 & - \\
\hline Torsional stiffness $(\mathrm{N} \cdot \mu \mathrm{m} / \mathrm{rad})$ & - & - & - & $9.5 e 5 / 6.9 e 5$ & $1.2 e 9 / 4.3 e 8$ & 9238 \\
\hline Support stiffness $(\mathrm{N} / \mu \mathrm{m})$ & $6.2 / 2241$ & - & $158.8 / 115.4$ & - & - & - \\
\hline
\end{tabular}

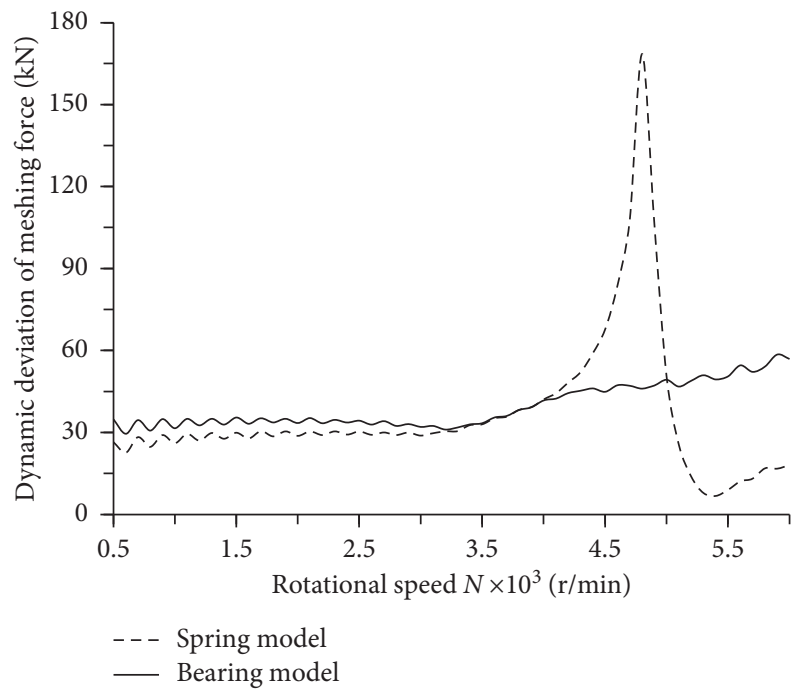

(a)

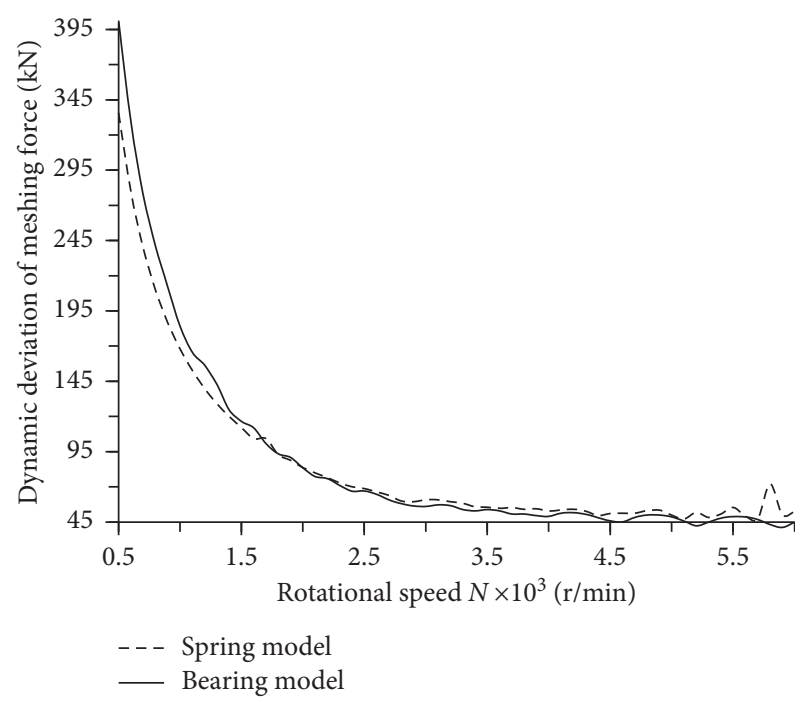

(c)

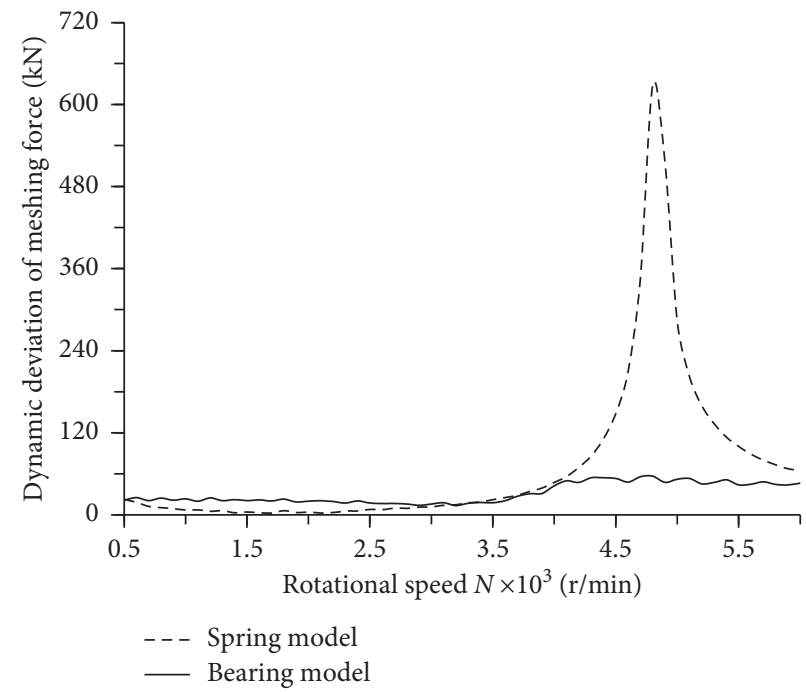

(b)

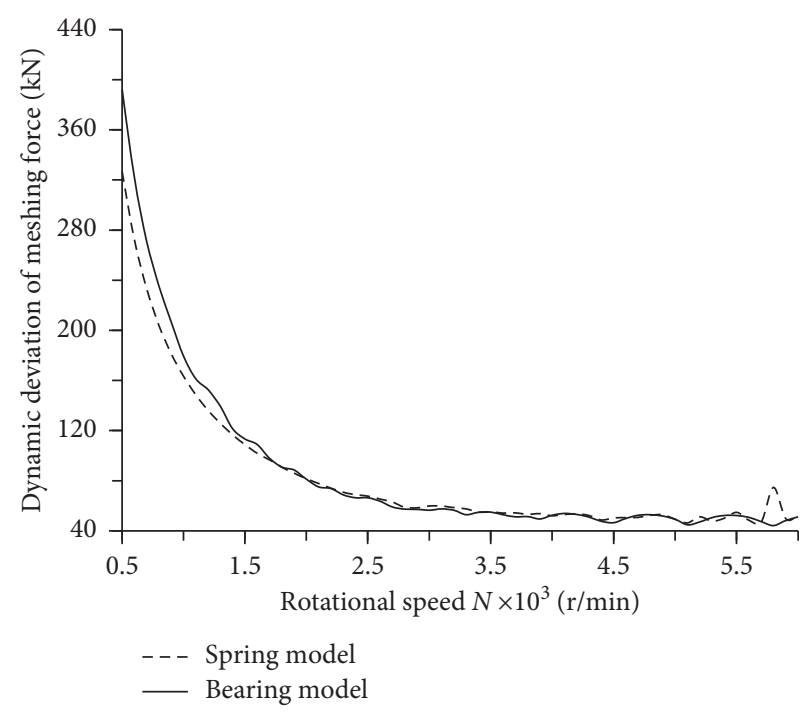

(d)

FIGURE 5: The dynamic deviation of meshing force: (a) external dynamic deviation of the differential stage, (b) internal dynamic deviation of the differential stage, (c) external dynamic deviation of the encased stage, and (d) internal dynamic deviation of the encased stage.

curves of meshing forces within the rotation speed range of 500-6000 r/min, as shown in Figure 7.

It can be seen from Figure 7 (a) that, for different eccentricity ratios of the differential planet bearing, amplitudefrequency response curves are basically consistent. This finding indicates that the eccentricity ratio of the differential planet bearing has little effect on the external meshing force in the differential planetary gear train. Figure 7 (b) reveals that amplitude-frequency response curves tend to diverge when the rotational speed is between $2000 \mathrm{r} / \mathrm{min}$ and $5000 \mathrm{r} /$ min. This result indicates that when the rotational speed is between $2000 \mathrm{r} / \mathrm{min}$ and $5000 \mathrm{r} / \mathrm{min}$, the eccentricity ratio of 


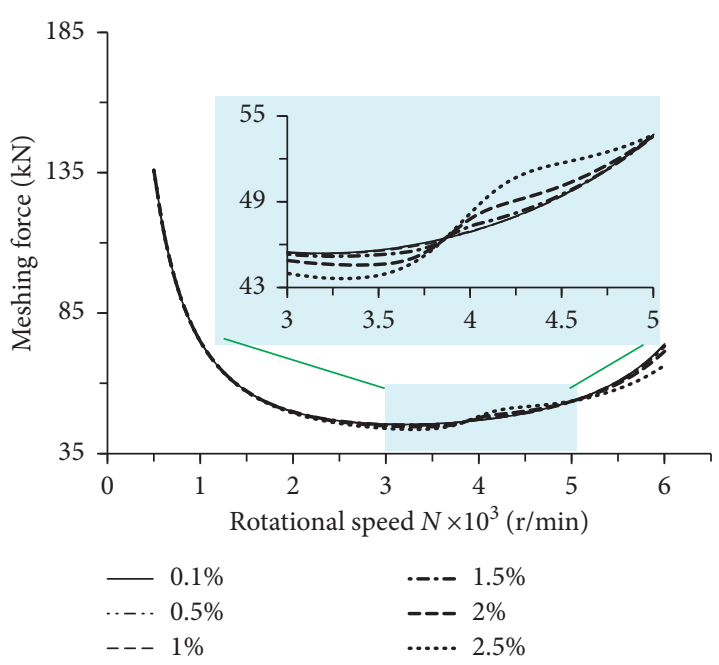

(a)

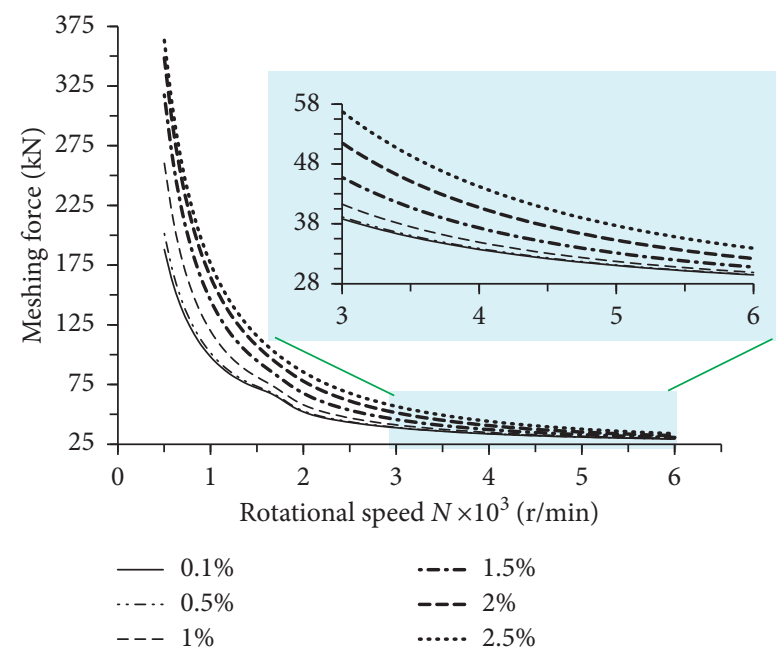

(c)

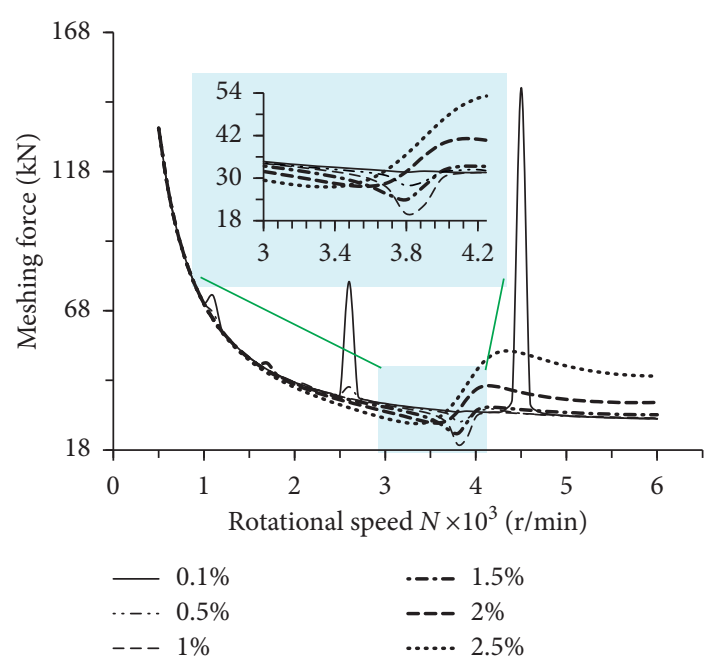

(b)

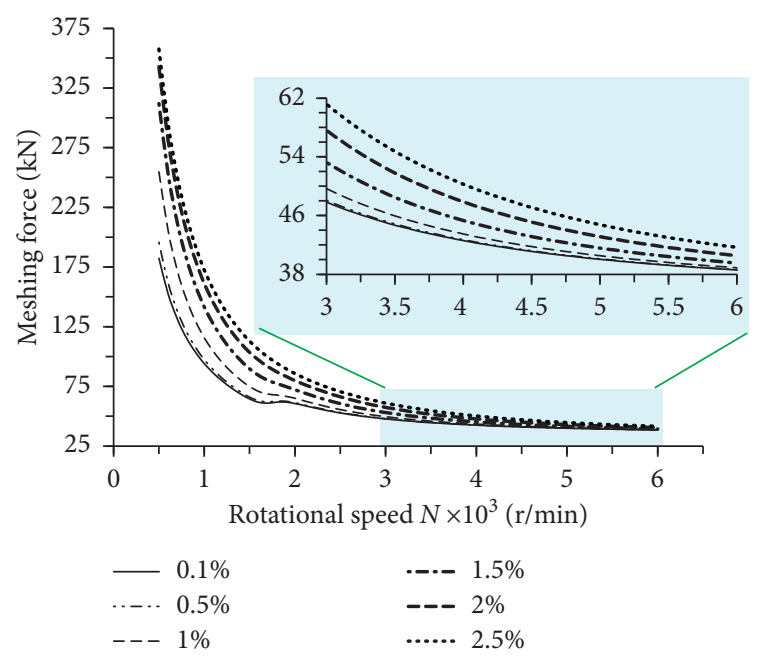

(d)

Figure 6: Amplitude-frequency response curves of meshing forces under different clearance-to-radius ratios of the differential planet bearing: (a) external meshing force of the differential stage, (b) internal meshing force of the differential stage, (c) external meshing force of the encased stage, and (d) internal meshing force of the encased stage.

the differential planet bearing has a significant influence on the internal meshing force in the differential stage. Amplitude-frequency response curves tend to diverge at low rotational speed and tend to overlap at high rotational speed (see Figures $7(\mathrm{c})$ and $7(\mathrm{~d})$ ), suggesting that the impact of eccentricity ratio of the differential planet bearing on the meshing forces in the encased stage is obvious when the rotational speed is low.

\subsection{Influence of the Encased Planet Bearing Parameters on Meshing Forces}

3.3.1. Clearance-to-Radius Ratio. In this section, the impact of clearance-to-radius ratios of the encased planet bearing on meshing forces is explored. Similar to the differential planet bearing, we set the clearance-to-radius ratio of the encased planet bearing as $0.1 \% 0,0.5 \% 0,1 \% 0,1.5 \%$, $2 \%$, and $2.5 \%$, respectively, as shown in Figure 8 .

Figures 8(a) and 8(b) uncover that the amplitude-frequency response curves of meshing forces (i.e., external and internal) in the differential stage are substantially uniform for different clearance-to-radius ratios of the encased planet bearing. Figures $8(\mathrm{c})$ and $8(\mathrm{~d})$ show that the amplitude-frequency response curves of meshing forces in the encased stage tend to overlap at low rotational speed and tend to diverge at a high rotational speed. It is worth noting that the amplitude-frequency response curves of meshing forces in the encased stage have a peak when the rotational speed is between $1500 \mathrm{r} /$ $\mathrm{min}$ and $2000 \mathrm{r} / \mathrm{min}$. These findings indicate that when the rotational speed is between $1500 \mathrm{r} / \mathrm{min}$ and $2000 \mathrm{r} /$ min, the clearance-to-radius ratio of the encased planet bearing has an obvious impact on the meshing forces in 


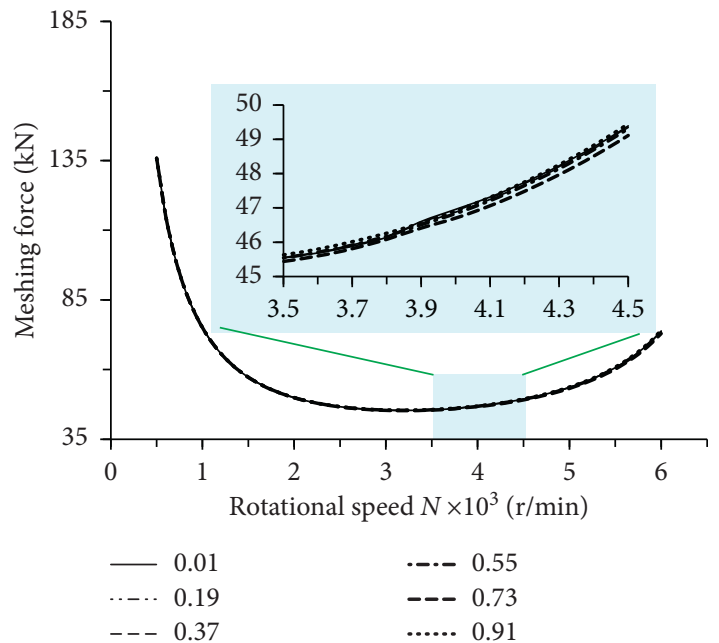

(a)

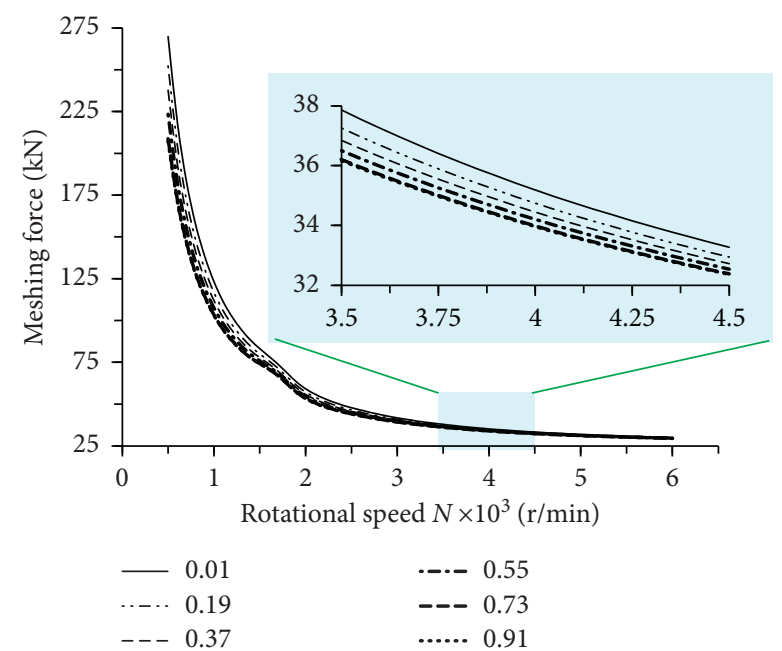

(c)

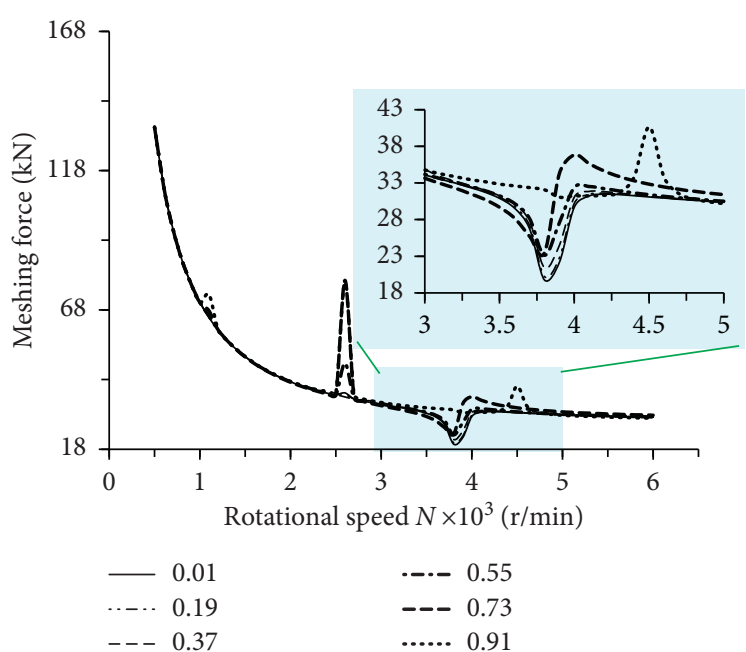

(b)

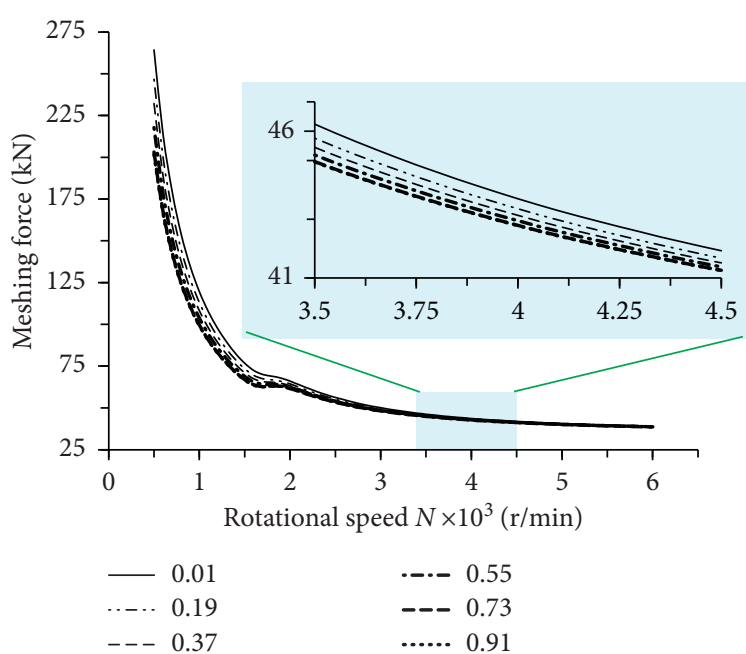

(d)

Figure 7: Amplitude-frequency response curves of meshing forces under different eccentricity ratios of the differential planet bearing: (a) external meshing force of the differential stage, (b) internal meshing force of the differential stage, (c) external meshing force of the encased stage, and (d) internal meshing force of the encased stage.

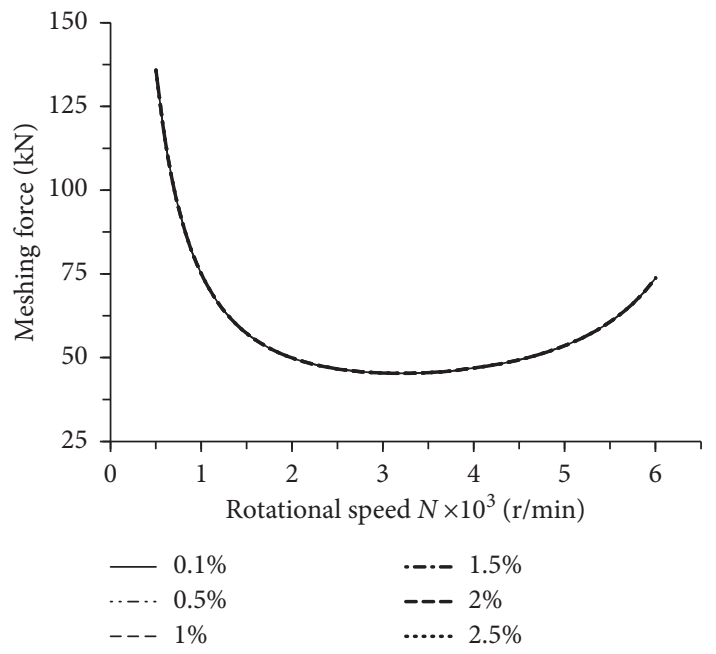

(a)

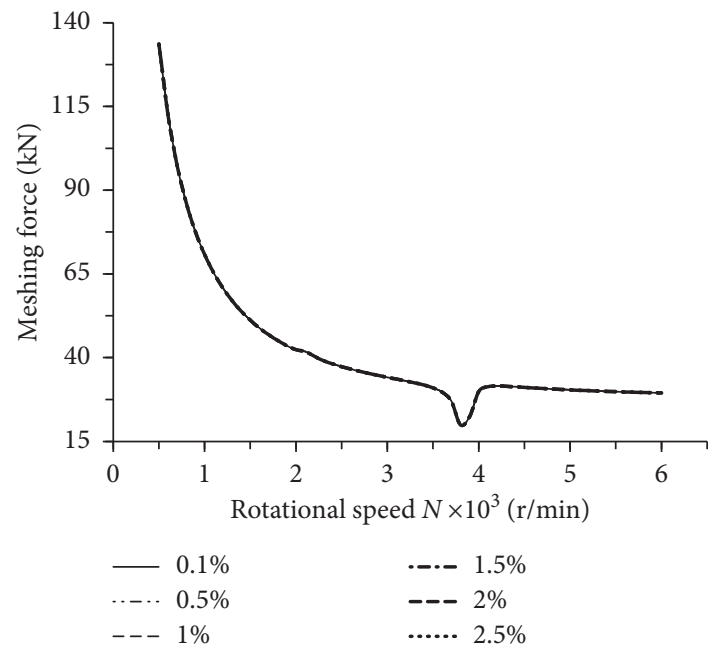

(b)

Figure 8: Continued. 


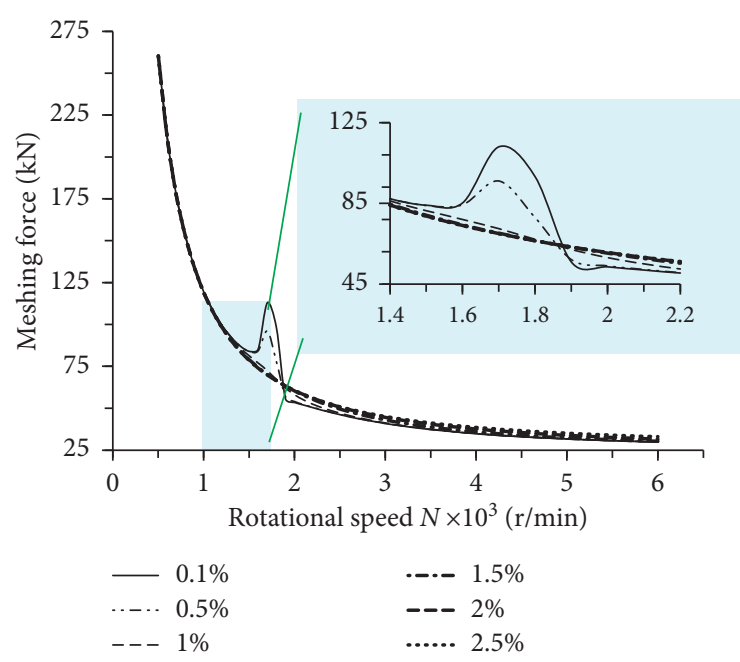

(c)

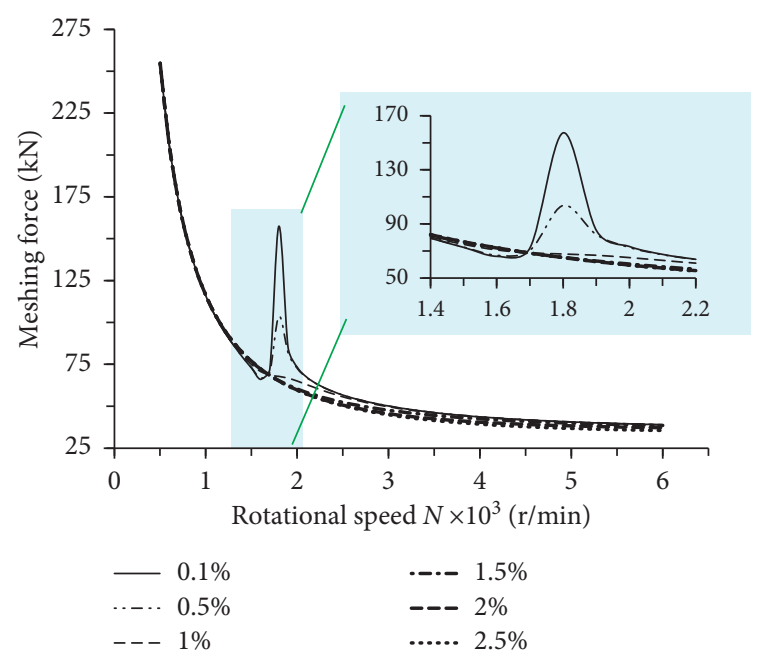

(d)

FIGURE 8: Amplitude-frequency response curves of meshing forces under different clearance-to-radius ratios of the encased planet bearing: (a) external meshing force of the differential stage, (b) internal meshing force of the differential stage, (c) external meshing force of the encased stage, and (d) internal meshing force of the encased stage.

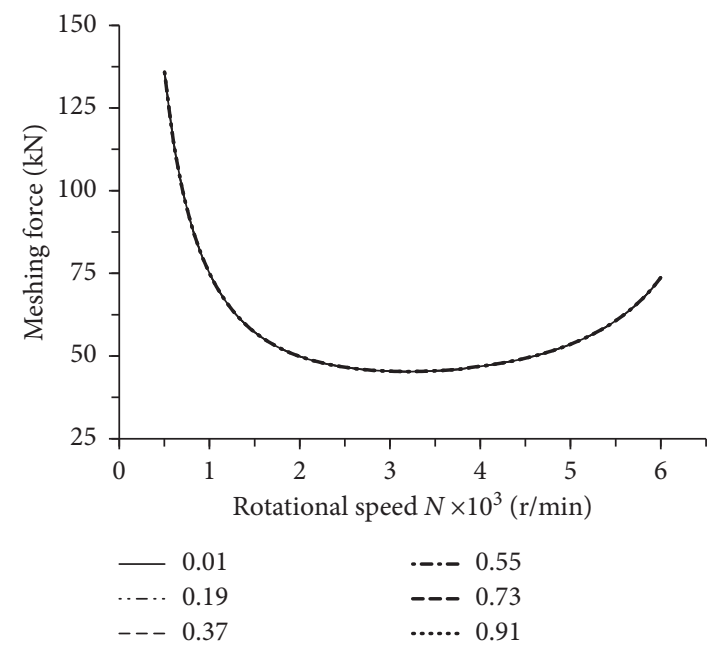

(a)

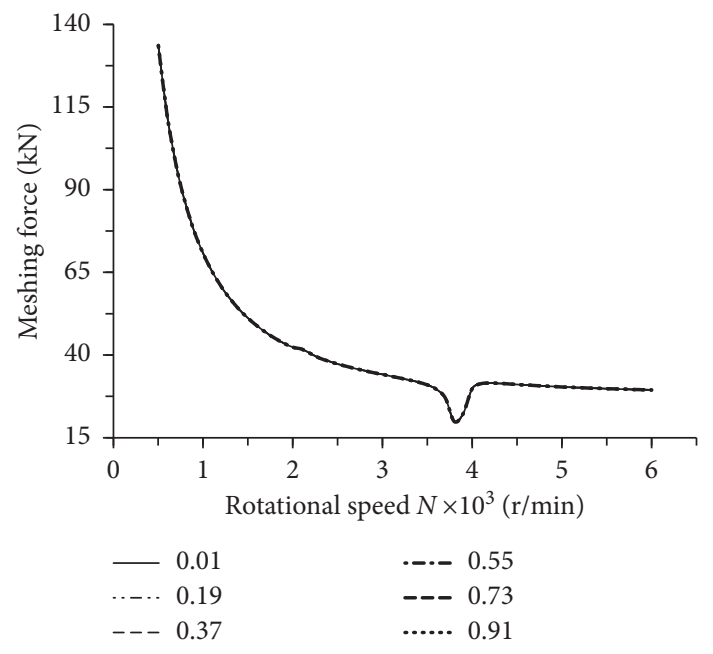

(b)

FIgUre 9: Continued. 


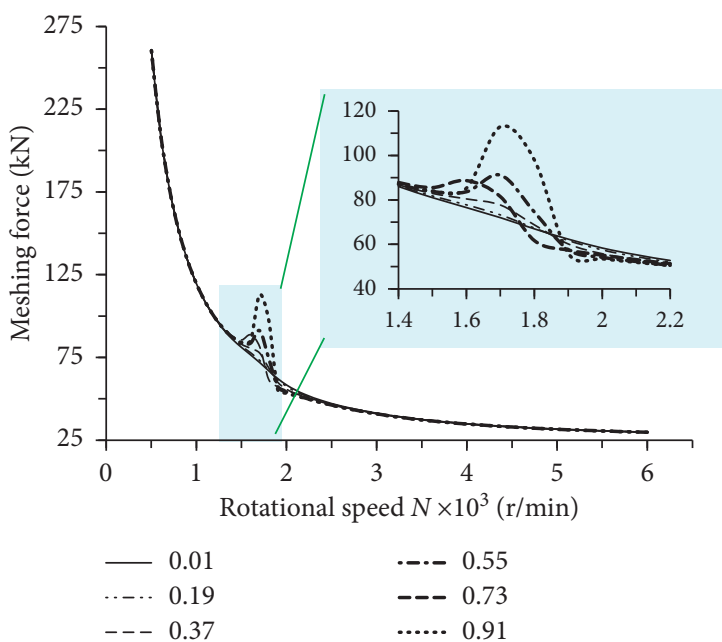

(c)

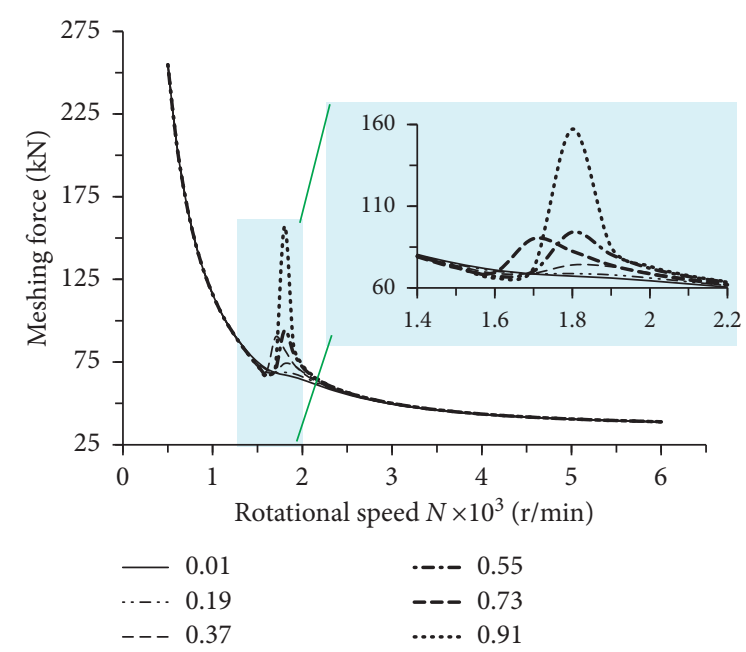

(d)

Figure 9: Amplitude-frequency response curves of meshing forces under different eccentricity ratios of the encased planet bearing: (a) external meshing force of the differential stage, (b) internal meshing force of the differential stage, (c) external meshing force of the encased stage, and (d) internal meshing force of the encased stage.

the encased stage, especially $1 \%$ and $0.5 \%$ clearance-toradius ratios.

3.3.2. Eccentricity Ratio. Using the same eccentricity parameters as in Section 3.2.2, the impact of the eccentricity ratio of the encased planet bearing on dynamic meshing forces is investigated, as shown in Figure 9.

Figures 9(a) and 9(b) show that the corresponding amplitude-frequency response curves are the same regardless of which eccentricity ratio of the encased planet bearing is incorporated into our model. Similar to the clearance-toradius ratio of the differential planet bearing, the eccentricity ratio of the encased planet bearing has a significant impact on the meshing forces in the encased stage when the rotational speed is between $1500 \mathrm{r} / \mathrm{min}$ and $2000 \mathrm{r} / \mathrm{min}$ (see Figures $9(\mathrm{c})$ and $9(\mathrm{~d})$ ). Besides, the eccentricity ratio of the encased planet bearing has more influence on the internal meshing force than on the external meshing force. Compared with Section 3.2.2, it can be found that the influence of the eccentricity ratio of the encased planet bearing on the meshing force of the encased stage is more significant than that of the differential stage.

\section{Conclusions}

Considering the factors of time-varying meshing stiffness and comprehensive transmission error, the dynamic model of encased differential gear train with journal bearing is established. The asymmetry and interaction of the oil film stiffness and damping of the planet bearings are employed in this dynamic model. The effects of planet bearing parameters on the meshing forces are explored, and the main conclusions are drawn as follows.

When the rotational speed is low, the stability of the encased differential gear train with journal bearing is basically the same as that of the encased differential gear train with spring. However, when the rotational speed is high, the encased differential gear train with journal bearing is more stable than the encased differential gear train with spring.

The clearance-to-radius and eccentricity ratio of the differential planet bearings affect the meshing forces of both the differential stage and encased stage. When the rotational speed is low, the influence of the clearance ratio and eccentricity ratio of the differential planet bearings on the meshing forces of the differential stage is less than that of the encased stage. However, this phenomenon is the opposite when the rotational speed is high.

The clearance-to-radius and eccentricity ratio of the encased planet bearing obviously affect the forces meshing of the encased stage, while they slightly affect the meshing forces of the differential stage. When the rotational speed is between $1400 \mathrm{r} / \mathrm{min}$ and $2000 \mathrm{r} / \mathrm{min}$, the clearance-to-radius and eccentricity ratio of the encased planet bearing have a significant impact on the meshing forces of the encased stage.

\section{Nomenclature}

$T_{D} / T_{L}: \quad$ Input/output torque

N/M: $\quad$ Teeth number of planets of the differential/ encased stage

$Z_{s 1} / Z_{s 2}: \quad$ Sun gear of the differential/encased stage

$Z_{p i} / Z_{m j}:$ The $i$ th $/ j$ th planet

$Z_{r 1} / Z_{r 2}$ : Composting ring gear of the differential/encased stage

$Z_{f 1} / Z_{f 2}$ : Floating ring gear of the differential/encased stage

$Z_{g 1} / Z_{g 2}$ : Intermediate floating member of the differential/ encased stage

$\mathrm{Z}_{s} / Z_{r}: \quad$ Teeth number of the sun/ring 
$T_{m} / t: \quad$ Meshing period/time

$r_{\mathrm{s} 1 \mathrm{~b}} / r_{\mathrm{s} 2 \mathrm{~b}}:$ Base circle radius of $Z_{\mathrm{s} 1} / Z_{\mathrm{s} 2}$

$r_{\mathrm{f} 1 \mathrm{~b}}: \quad$ Pitch circle radius of $Z_{f 1}$

$r_{\mathrm{c}}: \quad$ Rotation radius of planet

$k_{0}$ : $\quad$ Average meshing stiffness

$\alpha_{n} / \beta: \quad$ Pressure/helical angle of gear

$\varepsilon_{\alpha} / \varepsilon_{\beta}: \quad$ End-face/axial contact ratio

$\beta_{b}$ : $\quad$ Helical angle of the base circle

$\psi_{i} / \psi_{j}: \quad$ Phase angle of $Z_{p i} / Z_{m j}: \psi_{i}=2 \pi(i-1) / N$, $\psi_{i}=2 \pi(j-1) / M$

$\alpha_{r p}: \quad$ Meshing angle of $Z_{s 1}-Z_{p i}$

$\alpha_{s p}: \quad$ Meshing angle of $Z_{r 1}-Z_{p i}$

$\alpha_{s m}: \quad$ Meshing angle of $Z_{\mathrm{s} 2}-Z_{m j}$

$\alpha_{r m}: \quad$ Meshing angle of $Z_{\mathrm{r} 2}-Z_{m j}$

$e_{s p i}: \quad$ Equivalent error of $Z_{r 1}-Z_{p i}$

$e_{r p i}: \quad$ Equivalent error of $Z_{r 1}-Z_{p i}$

$e_{s m j}: \quad$ Equivalent error of $Z_{s 2}-Z_{m j}$

$e_{r m j}: \quad \quad$ Equivalent error of $Z_{r 2}-Z_{m j}$

$K_{s 1} / K_{s 2}$ : Supporting stiffness of $Z_{s 1} / Z_{s 2}$

$K_{r 1} / K_{r 2}$ : Supporting stiffness of $Z_{r 1} / Z_{r 2}$

$K^{H}{ }_{\xi \eta} / \quad$ Stiffness/damping of carrier bearing $(\xi, \eta=X, Y)$

$D^{H}{ }_{\xi \eta}$ :

$K^{p}{ }_{\xi \eta} l$

$D^{p_{\xi \eta}}$ :

$K^{m}{ }_{\xi \eta} l$

$D^{m}{ }_{\xi \eta}$ :

$K_{f 1 s 2}$ :

$K_{f 2 H}:$

$K_{g 1 q}$ :

$K_{f 1 q}$ :

$K_{g 2 q}$ :

$K_{\mathrm{f} 2 \mathrm{q}}$ :

$K_{\text {rpi }}$ :

$K_{s p i}$ :

$K_{r m j}$ :

$K_{s m j}$ :

$D_{r p}$ :

$D_{s p}$ :

$D_{r m}$ :

$D_{s m}$ :

$m_{s 1} / M_{s 1}$ :

$m_{p} / M_{p}$ :

$m_{r 1} / M_{r 1}$ :

$m_{\mathrm{g} 1} / m_{\mathrm{f} 1}$ :

$m_{\mathrm{s} 2} / M_{\mathrm{s} 2}$ :

$m_{m} / M_{m}$ :

$m_{r 2} / M_{r 2}$ :

$m_{g 2} / m_{f 2}$ :

$m_{c} / M_{c}$ :

Stiffness/damping of the $i$ th planet bearing $(\xi$, $\eta=H, V)$

Stiffness/damping of the $j$ th planet bearing $(\xi$, $\eta=H, V)$

Connection torsion stiffness of $Z_{f 1}-Z_{s 2}$

Connection torsion stiffness of $Z_{f 2}-H$

Contact tangential stiffness of $Z_{f 1}-Z_{g 1}$

Contact tangential stiffness of $Z_{g 1}-Z_{r 1}$

Contact tangential stiffness of $Z_{f 2}-Z_{g 2}$

Contact tangential stiffness of $Z_{g 2}-Z_{r 2}$

Time-varying meshing stiffness of $Z_{r 1}-Z_{p i}$

Time-varying meshing stiffness of $Z_{s 1}-Z_{p i}$

Time-varying meshing stiffness of $Z_{r 2}-Z_{m j}$

Time-varying meshing stiffness of $Z_{s 2}-Z_{m j}$

Meshing damping of $Z_{r 1}-Z_{p i}$

Meshing damping of $Z_{s 1}-Z_{p i}$

Meshing damping of $Z_{r 2}-Z_{m j}$

Meshing damping of $Z_{s 2}-Z_{m j}$

Equivalent/actual mass of $Z_{s 1}$

Equivalent/actual mass of $Z_{p i}$

Equivalent/actual mass of $Z_{r 1}$

Equivalent mass of $Z_{g 1} / Z_{f 1}$

Equivalent/actual mass of $Z_{s 2}$

Equivalent/actual mass of $Z_{m j}$

Equivalent/actual mass of $Z_{r 2}$

Equivalent mass of $Z_{g 2} / Z_{f 2}$

Equivalent/actual mass of $H$.

\section{Data Availability}

The data used to support the findings of this study are available from the corresponding author upon request.

\section{Conflicts of Interest}

The authors declare that there are no conflicts of interest regarding the publication of this paper.

\section{Acknowledgments}

This work was supported by the National Key R\&D Program of China (no. 2018YFB2001300) and National Natural Science Foundation of China (no. 51775265).

\section{References}

[1] L. H. Yang, W. M. Wang, S. Q. Zhao et al., "A new nonlinear dynamic analysis method of rotor system supported by oilfilm journal bearings," Applied Mathematical Modelling, vol. 38, no. 21-22, pp. 5239-5255, 2014.

[2] S. Baguet and G. Jacquenot, "Nonlinear couplings in a gearshaft-bearing system," Mechanism and Machine Theory, vol. 45, no. 12, pp. 1777-1796, 2010.

[3] H. Gao and Y. Zhang, "Nonlinear behavior analysis of geared rotor bearing system featuring confluence transmission," Nonlinear Dynamics, vol. 76, no. 4, pp. 2025-2039, 2014.

[4] S. Theodossiades and S. Natsiavas, "On geared rotordynamic systems with oil journal bearings," Journal of Sound and Vibration, vol. 243, no. 4, pp. 721-745, 2001.

[5] C. Wan and J. Chang, "Bifurcation and chaos of gear-rotor bearing system lubricated with couple-stress fluid," Nonlinear Dynamics, vol. 79, no. 1, pp. 749-763, 2015.

[6] Y. Guo and R. G. Parker, "Purely rotational model and vibration modes of compound planetary gears," Mechanism and Machine Theory, vol. 45, no. 3, pp. 365-377, 2010.

[7] D. L. Zhang, R. P. Zhu, B. B. Fu et al., "Modal properties of contra-rotating encased differential gear train used in coaxial helicopter," Journal of Vibration Engineering \& Technologies, 2019.

[8] S. Wu, H. Zhang, X. Wang, Z. Peng, K. Yang, and W. Zhu, "Influence of the backlash generated by tooth accumulated wear on dynamic behavior of compound planetary gear set," Proceedings of the Institution of Mechanical Engineers, Part C: Journal of Mechanical Engineering Science, vol. 231, no. 11, pp. 2025-2041, 2017.

[9] Z. Zhu, L. Cheng, R. Xu, and R. Zhu, "Impacts of backlash on nonlinear dynamic characteristic of encased differential planetary gear train," Shock and Vibration, vol. 2019, Article ID 9347925, 15 pages, 2019.

[10] J. Lin and R. G. Parker, "Planetary gear parametric instability caused by mesh stiffness variation," Journal of Sound and Vibration, vol. 249, no. 1, pp. 129-145, 2002.

[11] A. Al-Shyyab, K. Alwidyan, A. Jawarneh, and H. Tlilan, "Nonlinear dynamic behaviour of compound planetary gear trains: model formulation and semi-analytical solution," Proceedings of the Institution of Mechanical Engineers, Part K: Journal of Multi-Body Dynamics, vol. 223, no. 3, pp. 199-210, 2009.

[12] L. Xiang, N. Gao, and A. Hu, "Dynamic analysis of a planetary gear system with multiple nonlinear parameters," Journal of Computational and Applied Mathematics, vol. 327, pp. 325340, 2018.

[13] M. Iglesias, A. Fernandez del Rincon, A. de-Juan, P. Garcia, A. Diez-Ibarbia, and F. Viadero, "Planetary transmission load sharing: manufacturing errors and system configuration study," Mechanism and Machine Theory, vol. 111, pp. 21-38, 2017.

[14] S. Mo, Y. Zhang, Q. Wu, S. Matsumura, and H. Houjoh, "Load sharing behavior analysis method of wind turbine gearbox in consideration of multiple-errors," Renewable Energy, vol. 97, pp. 481-491, 2016.

[15] H. Zhai, C. Zhu, C. Song, H. Liu, and H. Bai, "Influences of carrier assembly errors on the dynamic characteristics for 
wind turbine gearbox," Mechanism and Machine Theory, vol. 103, pp. 138-147, 2016.

[16] M. Maatar and P. Velex, "An analytical expression for the time-varying contact length in perfect cylindrical gears: some possible applications in gear dynamics," Journal of Mechanical Design, vol. 118, no. 4, pp. 586-589, 1996.

[17] D. Zhang, R. Zhu, B. Fu, and W. Tan, "Mesh phase analysis of encased differential gear train for coaxial twin-rotor helicopter," Mathematical Problems in Engineering, vol. 2019, Article ID 8421201, 9 pages, 2019.

[18] R. G. Parker and J. Lin, "Mesh phasing relationships in planetary and epicyclic gears," Journal of Mechanical Design, vol. 126, no. 2, pp. 365-370, 2004.

[19] S. Wu, M. J. Zuo, and A. Parey, "Simulation of spur gear dynamics and estimation of fault growth," Journal of Sound and Vibration, vol. 317, no. 3-5, pp. 608-624, 2008.

[20] Z. Fang, Y. Shen, and Z. Huang, "The dynamic behavior of star gearing with three branches," Acta Aeronautica Et Astronautica Sinica, vol. 11, no. 7, pp. 341-250, 1990.

[21] V. Abousleiman, P. Velex, and S. Becquerelle, "Modeling of spur and helical gear planetary drives with flexible ring gears and planet carriers," Journal of Mechanical Design, vol. 129, no. 1, pp. 95-106, 2007. 